\title{
Structural reliability assessment based on optical monitoring system: case study
}

\section{Avaliação da fiabilidade estrutural baseado em sistema ótico de monitorização: caso de estudo}
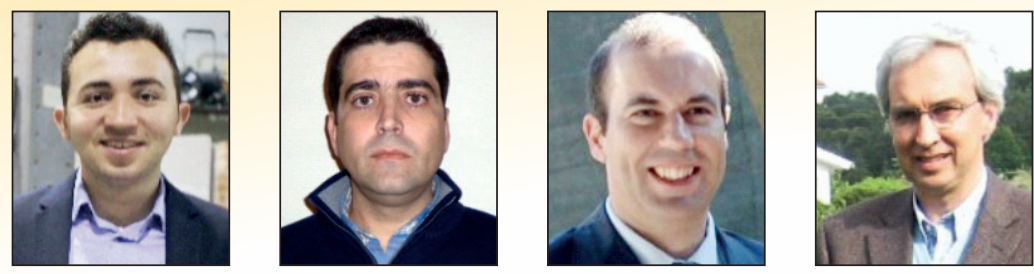

E. MESQUITA a e.mesquita@fe.up.pt

P. ANTUNES a

pantunes@ua.pt
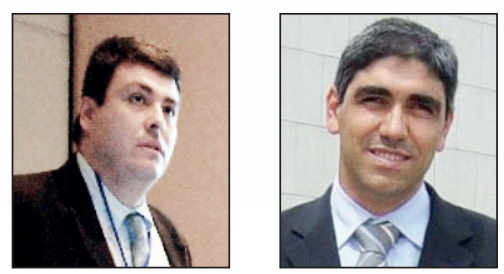

A. A. HENRIQUES abel.henriques@fe.up.pt

A. ARÊDE a

aarede@fe.up.pt

P. S. ANDRÉ b paulo.andre@ist.utl.pt

H. VARUM hvarum@fe.up.pt

\section{Abstract}

Optical systems are recognized to be an important tool for structural health monitoring, especially for real time safety assessment, due to simplified system configuration and low cost when compared to regular systems, namely electrical systems. This work aims to present a case study on structural health monitoring focused on reliability assessment and applying data collected by a simplified optical sensing system. This way, an elevated reinforced concrete water reservoir was instrumented with a bi-axial optical accelerometer and monitored since January 2014. Taking into account acceleration data, the natural frequencies and relative displacements were estimated. The reliability analysis was performed based on generalized extreme values distribution (GEV) and the results were employed to build a forecast of the reliability of the water elevated reservoir for the next 100 years. The results showed that the optical system combined with GEV analysis, implemented in this experimental work, can provide adequate data for structural reliability assessment.

Keywords: optical sensors, remote control, natural frequency, reliability assessment, generalized extreme values distribution.

\section{Resumo}

Sistemas óticos são reconhecidos como uma importante ferramenta para a monitorização estrutural, especialmente para avaliação da segurança em tempo real, devido a configuração simplificada e o baixo custo destes sistemas quando comparado com sistemas usuais, nomeadamente sistemas elétricos. Este trabalho tem por objetivo apresentar um caso de estudo sobre monitorização estrutural focado na avaliação da fiabilidade através da utilização de um sistema sensorial ótico simplificado. Dessa forma, um reservatório elevado de água de concreto armado foi instrumentado com um acelerómetro ótico biaxial e monitorado desde janeiro de 2014. Tendo em conta os dados de aceleração, as frequências naturais e os deslocamentos relativos foram calculados. Neste trabalho, a análise de fiabilidade é realizada baseada na distribuição de valores extremos e os resultados obtidos são ainda utilizados para a predição sobre a segurança estrutural do reservatório de água para os próximos 100 anos. Os resultados mostraram que o sistema ótico de monitorização implementado neste trabalho combinado com a análise por distribuição dos valores extremos pode fornecer dados adequados para a avaliação da fiabilidade estrutural.

Palavras-chave: sensor ótico, controle remoto, frequência natural, análise da fiabilidade, distribuição de valores extremos. 


\section{Introduction}

The recent codes ABNT NBR 15575 [1] and EN 1990 [2] establish the safety minimum coefficients that structures should attend to during their service life for keeping their safety. However, the current design codes introduce a high number of uncertainties to existing structures, essentially associated to material properties, loadings and work scenarios. Thereby, the employment of structural health monitoring (SHM) can be an interesting tool for structural characterization, because SHM can offer accurate data for the structural behavior in real time.

SHM systems are composed by three principal systems that are: sensorial system, data receiving system and data processing system. In fact, in the recent years the sensors have been advancing towards more compact systems, better levels of data accuracy and less signal interferences. In this way, a large number of optical sensors were implemented [3]-[6] since the year 2000 , essentially motivated by their relatively low cost, the possibility of sensors multiplexing, their immunity to interference from electromagnetic fields and because the optical sensors can be less intrusive than electrical sensors.

According to Diamantidis [7] the reliability assessment has as main aim the prediction of the structure's failure probability under a determinate scenario, taking into account the limit state service or ultimate limit service, and also methods based on probabilistic models, due to high level of uncertainties associated with random variables [8]. Thus, the employment of SHM systems with probabilistic methods can be an interesting and important tool for risk prevention, being possible the structural performance characterization under real service conditions, as well as the prediction about the structural behavior under dramatic scenarios.

In this context, Dissanayake e Karunananda [9] proposed a new method for reliability analysis based on element failure and reinforcement corrosion, and their method was applied to a railway bridge, in Sri Lanka, with $160 \mathrm{~m}$ of length. The results showed that the probabilistic model developed by the authors presents a good model for failure due to decreasing of the reinforcement area by corrosion process and element failure. Another similar study related with SHM systems combined with reliability analysis is reported by Liu et al [10], where a railway bridge on the Wisconsin river, in the United States, was instrumented with strain gauges and the traffic loads effect on the bridge's behavior was monitored. The data from the SHM system implemented on the bridge allowed the evaluation of reliability index in the current state, and were also used to predict the bridge's reliability performance for the next 20 years. However, the cost of the sensing systems employed in both works mentioned above could have been minimized if optical sensors had been employed.

In order to contribute for reliability assessment, this work presents a simplified methodology for structural safety assessment based on an optical system, which consists of data selection, preliminary statistical analysis focused on histogram construction, probability assessment by GEV and determination of the failure probability. Thereby, an elevated reinforced concrete water reservoir located in Campus of Santiago, in the University of Aveiro, Portugal, was instrumented with a bi-axial optical accelerometer [11] and continuously monitored since January 2014. From the data collected by longitudinal and transversal accelerations, the relative structural displacements due to wind action were obtained and used as main variables for structural reliability analysis.

\section{Reliability assessment method based on relative displacements}

The use of probabilistic methods for structural performance assessment under a determinate scenario can be a relevant help tool for structural integrity and safety management. The probabilistic methods can be interesting due to the fact that in the construction phase, structures are associated to a large number of uncertainties which are not included in the current design codes and also present a difficulty modeling by deterministic methods, making necessary the resource to probabilistic methods, which are most adequate for random variables processing.

In fact, the employment of probabilistic methods for reliability assessment should be adopted because there are some uncertainties introduced by geometric and material characteristics, and also load combination that structures can be submitted to during their service life, and in these cases the probabilistic models can be used for modeling the variable set $[8,11,12]$. Generally, the set of variables involved in the structural reliability assessment are represented by $R$ and $E$, where $R$ represents the safety variable group for the analyzed scenario and $E$ represents the variable group which affects negatively the structural safety. Then the structural probability of failure, $\mathrm{Pf}$, can be written as:

$$
P f=\mathscr{P}\{g(R, E) \leq 0\}=\mathscr{P}\{r(R) \leq e(E)\}
$$

where, $g(R, E) \leq 0$ represents the limit failure condition.

So, considering expression (1) the failure probability, $\mathrm{Pf}$, can also be written according to expression (2), where $f \mathrm{x}$ is the probability density function of $X$, and $X$ represents all random variables from the problem in study.

$$
P f=\int_{g(x) \leq 0} f \mathrm{x}(x) d x
$$

From failure probability, $\mathrm{Pf}$, the reliability index $\beta$ can be estimated by expression (3), where $\phi^{-1}$ is the inverse of the standard normal distribution function.

$$
\beta=-\Phi^{-1}(P f)
$$

Especially for cases in which the set of variables are known for a determinate interval of time, and the maximum and minimum values of probabilistic curves need to be predicted, it is common to resort to generalized extremes values distribution (GEV)[8]. The employment of GEV in cases of probabilistic analysis is indicated when the number of data is sufficiently large and the frequency distribution curve is asymptotic. However, in order to consider the asymptotic types 
Figure 1 - Reinforced concrete water reservoir elevated of University of Aveiro (A), localization of reservoir in relation to Institute of Telecommunications of Aveiro (B), and detail of the position of the bi-axial optic accelerometer (C)

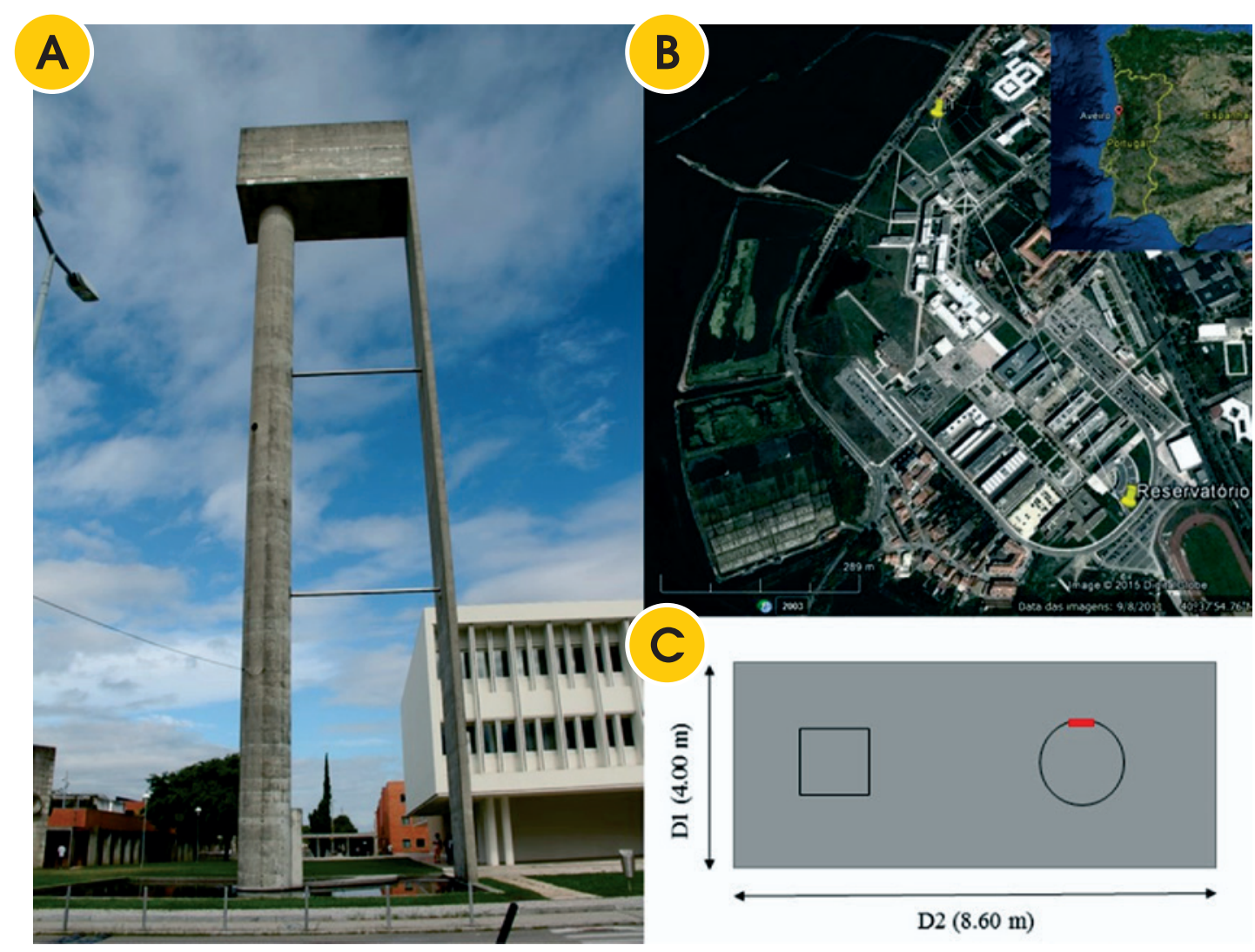

of curve that a data distribution can assume, one of the three forms of GEV should be adopted, namely: Gumbel distribution (Type I), Fréchet distribution (Type II) and Weibull distribution (Type III) [10]. The Gumbel distribution is based on the principle that the failure occurs when a determined set of values exceeds the safety value [8] and is frequently applied to modelling environmental phenomena, as for example wind velocity [14]; in addition the Gumbel distribution has been recently used in SHM systems for service life prediction $[8,11,13]$. The Gumbel distribution for maximum values can be defined by function Fx(x), according to expression (4), where $\alpha$ and $u$ can be estimated from the data set analyzed, and $x$ is the limit exceedance values in the distribution curve that will be analyzed. In fact, the $\alpha$ and $u$ values can be obtained by expressions (5) and (6), where the variance $\mathbb{V}(X)$ is a necessary value for determination of constant $\alpha$, and $\mathbb{E}(X)$ is the average of $\mathrm{Fx}(\mathrm{x})$ function, for a given value of $\mathrm{y}$ of 0.577 .

$F x(x)=\exp \left[-e^{-\alpha(x-u)}\right]$
$\mathbb{E}(X)=u+\frac{\gamma}{\alpha}$

$$
\mathbb{V}(X)=\frac{\pi^{2}}{6 \alpha^{2}}
$$

Thus, the method for structural reliability assessment proposed in this work, based on random variables from wind velocity, namely structural displacements due to wind action, follows the present sequence: 1) selection of a data set, 2) establishment of an $x$ limit value, in which the function $G(x) \leq 0$ represents failure, 3 ) construction of histograms based on obtained values from $G(x) \leq 0$ considering the limit value of $x, 4$ ) adoption of an adequate probabilistic distribution curve, 5 ) determination of the statistic variables $(\mathbb{E}, \mathbb{V}, \alpha e u), 6)$ determination of failure probability $\mathrm{Pf}$, taking in account the $x$ limit value and 7 ) evaluation of reliability index, $\beta$.

\section{Case study}

\subsection{Reinforced concrete elevated water reservoir}

The elevated water reservoir [Figure 1-A] is a slender structure of reinforced concrete with a height of $35.25 \mathrm{~m}$, built in 1989 in the campus of Santiago at University of Aveiro [Figure 1-B], Portugal, essentially composed by a laminar section of $30.90 \mathrm{~m}$ of height, 4 $\mathrm{m}$ of length and $0.30 \mathrm{~m}$ of thickness; one cylindrical hollow section with $30.90 \mathrm{~m}$ of height, outer diameter of $2.40 \mathrm{~m}$ and inner diameter of $1.20 \mathrm{~m}$; and a rectangular structure with $4.35 \mathrm{~m}$ of height, $8.60 \mathrm{~m}$ 
of longitudinal length and $4.00 \mathrm{~m}$ of transversal length. The present structure has a metallic bracing, composed by two hollow steel cylinders with $5 \mathrm{~mm}$ of thickness, placed at $1 / 3$ and $2 / 3$ of the total height. The reservoir instrumentation was done by employing a bi-axial optical accelerometer developed and tested by Antunes [15], positioned in the structure top, as shown in the [Figure 1- C]. The implemented monitoring system was connected to a data acquisition system located in the Institute of Telecommunications of Aveiro, Portugal, by $790 \mathrm{~m}$ of optical fiber [Figure 1-B].

In order to collect data on structural displacements due to wind action, the elevated reservoir has been monitored since January 2014 aiming the identification of changes in the structural behavior that can compromise the safety state. In this way, the bi-axial optic accelerometer has the function of collecting information in the transversal (D1) and longitudinal (D2) directions, essential accelerations for determining the natural frequency and relative displacements.

\subsection{Data collecting, selection and processing}

The natural frequency is given by the expression (7), where the mass $\mathrm{m}$ is characterized as inversely proportional of the square of the natural frequency, $f$, and directly proportional to square of the stiffness ratio $\mathrm{k}$. In this analysis the stiffness ratio $\mathrm{k}$ was considered constant, and that only the $m$ value could influence the frequency value, due to water level variation inside the water reservoir. The structural displacements were collected only for cases in which the wind presents the same direction. In this way, the wind action was restricted to southeast direction, in order to coincide with the structure's face with higher area, through which the wind action is supposed to present a greater effect on structure displacements in transversal and longitudinal directions.

$$
f=\frac{1}{2 \pi} \sqrt{\frac{k}{m}}
$$

From the data offered by bi-axial optic accelerometer, the linear relative displacements of the elevated reservoir were obtained according to expression (8), where $s(t)$ is the displacement in function of the time and $\mathrm{a}(\mathrm{t})$ represents the acceleration in function of the time.

$s(t)=a(t) d t$

The natural frequency spectrums of the elevated reservoir for each direction (D1 and D2) were obtained by the Fourier transform (9), where $\omega=2 \pi f$.

$$
X(\omega)=\int_{-\infty}^{\infty} f(t) e^{-i \omega t} d t
$$

From analysis of a large data set, were selected the wind actions described in $A$ and $B$, as shown in the [Table 1]. In D1 direction (transversal) the values of natural frequencies in the situation $A$ and $B$ presented the same frequency value, namely $0.900 \mathrm{~Hz}$. However, taking into account the greater length of D2 (longitudinal direction) relative to $\mathrm{D} 1$, the possible mass variation influenced by changes in the water level presented influence in the natural frequency value, respectively $0.787 \mathrm{~Hz}$ and $0.793 \mathrm{~Hz}$. The spectrums of the natural frequency collected are shown in [Figure 2], where $A$ and $B$ represent the wind behavior and D1 and D2 are transversal and longitudinal direction of the water reservoir respectively.

It is also important to refer that for each measurement realized were considered $105 \mathrm{~s}$ of data record time, that correspond to 200.000 acceleration points. Once the acceleration spectrum was known, the velocity and structural relative displacements in the transversal and longitudinal directions were obtained and considered in function of the time, as can be seen by [Figure 3].

In terms of data processing of structural relative displacements, the maximum values of structural displacements in both directions were obtained and processed as absolute values [Figure 4]. Then, a new data set was obtained and these values were employed in this work for evaluation of the reliability index.

Based in the relative displacements of the elevated reservoir under wind action, for both wind conditions $A$ and $B$, and also based in the relations stablished by expression (7), the structure presents a higher stiffness in the direction D2, for which smaller values of natural frequency already were expected.

\section{Structural reliability assessment}

From the maximum relative displacements in both directions D1 and D2, were obtained the histograms showed in the [Figure 5]. The histograms AD1 and BD1 refer to maximum displacements in the transversal direction, and the histograms AD2 and BD2 refer to maximum displacements in the longitudinal direction of the water reservoir, for wind characteristics according to condition $\mathrm{A}$ and $\mathrm{B}$. The direction $\mathrm{D} 1$ presents a more sensibility to wind action than the direction D2, for example, for wind velocity of 10.3

\section{Table 1 - Wind characterization for situations A and B and measures of natural frequencies of the water reservoir}

\begin{tabular}{cccccc} 
Identification & Data & $\begin{array}{c}\text { Wind velocity } \\
(\mathrm{m} . \mathrm{s}-1)\end{array}$ & Wind direction & $\begin{array}{c}\text { Transversal } \\
\text { direction }\end{array}$ & $\begin{array}{c}\text { Longitudinal } \\
\text { direction }\end{array}$ \\
A & $18 / 09 / 2014$ & 8,9 & SE & 0,9 & 0,787 \\
B & $14 / 02 / 2014$ & 10,30 & SE & 0,900 & 0,793 \\
\hline
\end{tabular}


$\mathrm{m} / \mathrm{s}$ in the SE direction the D1 maximum displacement is close of $0.0225 \mathrm{~m}$, while in the D2 direction the maximum displacement is close of $0.0125 \mathrm{~m}$. In fact, this maximums displacement values represent that the $\mathrm{D} 1$ direction is $180 \%$ more sensible to wind action than D2 direction.

In order to consider the frequency distribution of the maximum values of relative displacement of the elevated reservoir were drawn GEV curves, as can be seen in the [Figure 6]. Once the values of average $\mu$ and standard deviation $\delta$ for a data set of $X$ were calculated, the values of $\alpha$ and $u$ were found based in the expressions (5) and (6) and then employed in the expression (4) aiming the definition of the probabilistic function $\mathrm{Fx}(\mathrm{x})$. Finally the failure probabilities $\mathrm{Pf}$ were evaluated and the values of reliability index $\beta$ were found using expression (3), where $R$ was adopted as $0.03 \mathrm{~m}$, in accordance with the maximum limit displacement allowed for a structure defined by ABNT NBR 15575 [1].

In the [Figure 7] the reliability indexes $\beta$ are shown for two directions, D1 and D2, in function of the wind velocity in the southeast direction, in which is perceptible the decreasing in the reliability index according to the increase of the wind velocity. It is noted that, when the wind velocity changes from $8.9 \mathrm{~m} / \mathrm{s}$ to $10.8 \mathrm{~m} / \mathrm{s}$ in the direction D1 the $\beta$ values change 5.781 to 2.799 . In relation to D2 direction, for the same variation in the wind velocity the $\beta$ values present a variation 7.023 to 6.004 . This variation represents that when the wind velocity changes from $8.90 \mathrm{~m} / \mathrm{s}$ to $10.80 \mathrm{~m} / \mathrm{s}$ in the D2 direction the failure probability increases $14.50 \%$. However, the increase in the failure probability is more dramatic in the D1 direction, where it is observed that the wind velocity increase represents a $51.56 \%$ greater chance of structural failure, essentially by displacements from wind action.

The reliability indexes $\beta$ found by applying the proposed methodology for structural reliability assessment presented moderated values and this highlights the necessity of continuous monitoring of the water reservoir. Were found the $\beta$ values of 5.438 to $8.9 \mathrm{~m} / \mathrm{s}$ and 2.713 to $10.3 \mathrm{~m} / \mathrm{s}$ in the direction D1. Now, in the direction D2 were found the values of $\beta$ of 6.136 to $8.9 \mathrm{~m} / \mathrm{s}$ and 4.92 to 10.3 $\mathrm{m} / \mathrm{s}$. Nonetheless, the reliability indexes $\beta$ found by the application of GEV present confident results (Kolmogorov-Smirnoff < 0.05).

By expressions (10) and (11) a predictive study about the reliability index was performed by employment of the GEV data in the future, $\varepsilon_{x}(T)$, where $\varepsilon_{x}$ is the extreme value of a random variable, $\lambda$ and $\mathrm{n}$ are constants to be determined according to data measured by statistic or graphic methods, $\mathrm{T}$ is the return period and $\zeta(\mathrm{s}, \mathrm{t})$ is the ration between of the GEV data in the future, $\varepsilon_{x}(T)$, and the

\section{Figure 2 - Natural frequency collected for A and B wind behavior}
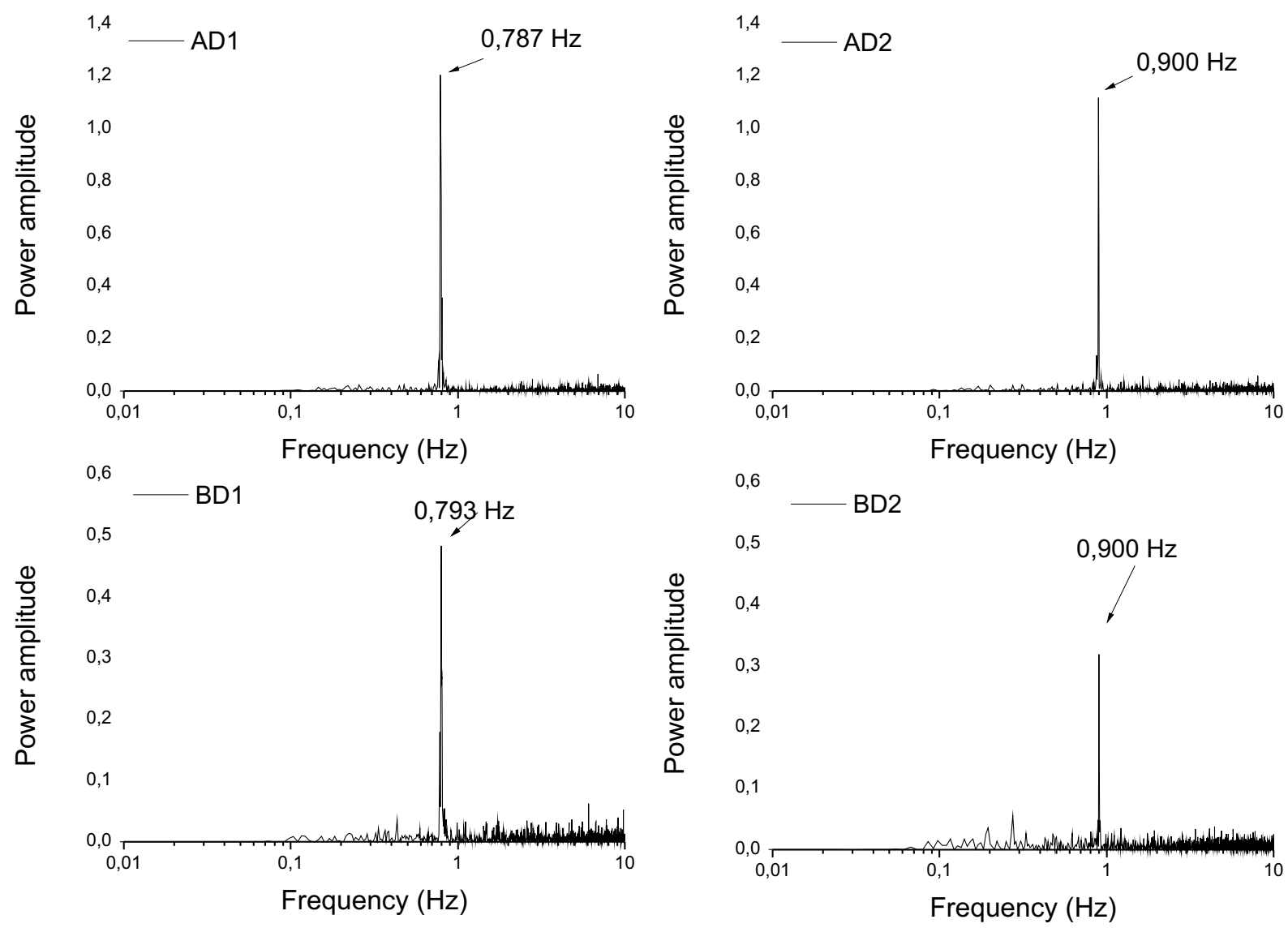
maximum values of $\varepsilon_{i}(i=1,2,3, \ldots k)$. For conservative considerations when the $\zeta(\mathrm{s}, \mathrm{t})$ value is less than 1 ., it should be assigned as 1.0 .

$$
\varepsilon_{x}(T)=\lambda-n \cdot \ln \left[-\ln \left(1-\frac{1}{T}\right]\right.
$$

$$
\zeta(s, t=T)=\frac{\varepsilon_{x}(T)}{\max \left(\varepsilon_{1}, \varepsilon_{2}, \varepsilon_{3} \ldots \varepsilon_{k}\right)}
$$

For the predictive reliability analysis, it was estimated that the annual number of times the water elevated reservoir is under conditions $A$ and $B$ is of 365 . This way, for the next t years it will be $T=365 \mathrm{X}$ t. [Figure 8] shows the results of the predictive reliability analysis for the next 5 , $10,15,20,25,50$ and 100 years. The details of the predictive analysis are shown in [Table 2]. It is important to highlight that in this study the decreases in the reliability index, $\beta$, are associated with the predicted maximum displacements provoked by wind actions. However, for a most accurate reliability prediction the results presented by Figure 8 should be associated with the water reservoir deterioration analysis.

\section{Conclusions}

This work presents a reliability monitoring system based on

Figure 3 - Spectra of acceleration, velocity and relative displacement in the transversal (DI) and longitudinal directions (D2) of the water elevated reservoir under wind action A and B
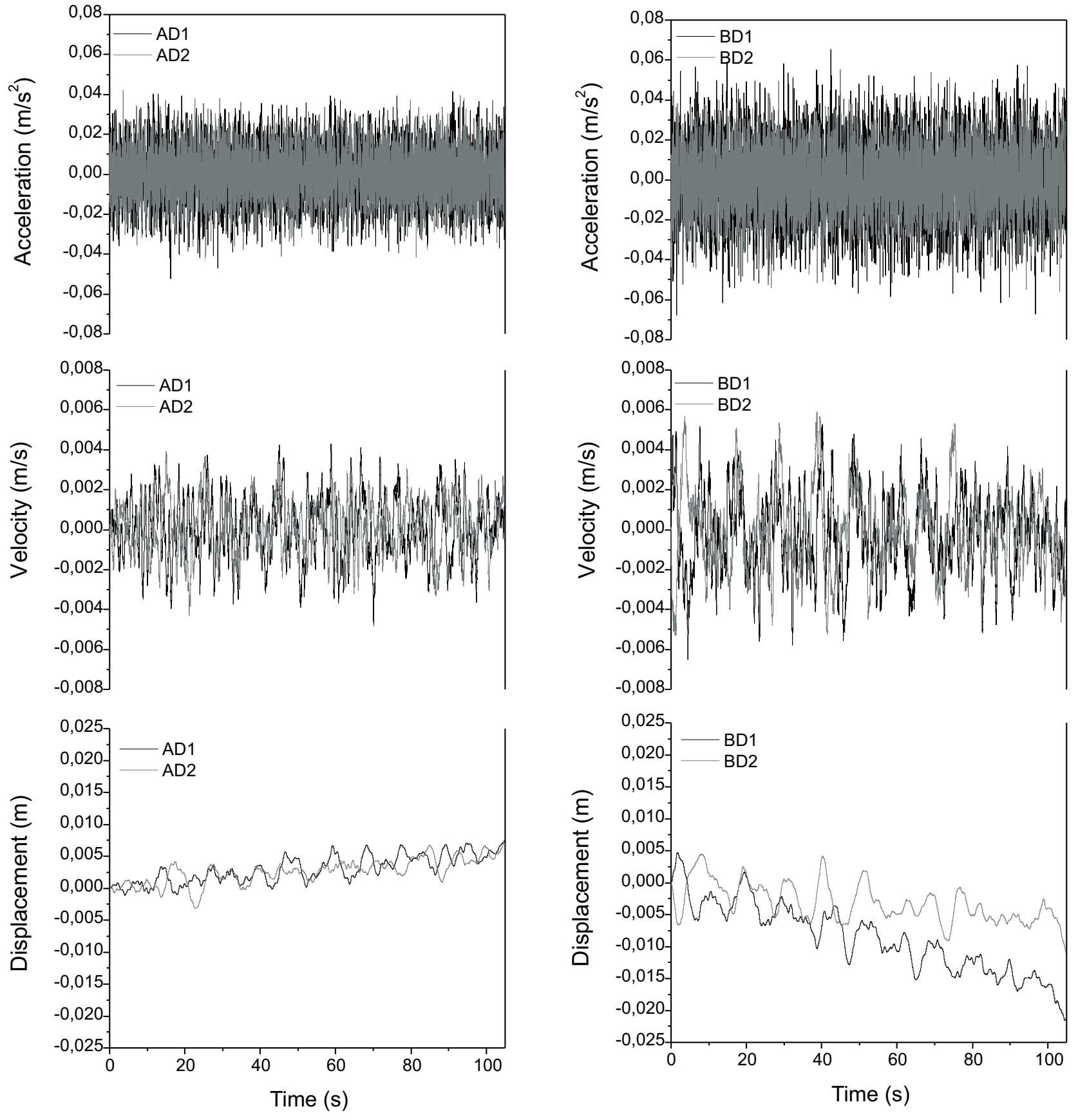
Figure 4 - Absolute values of the maximums relative displacement

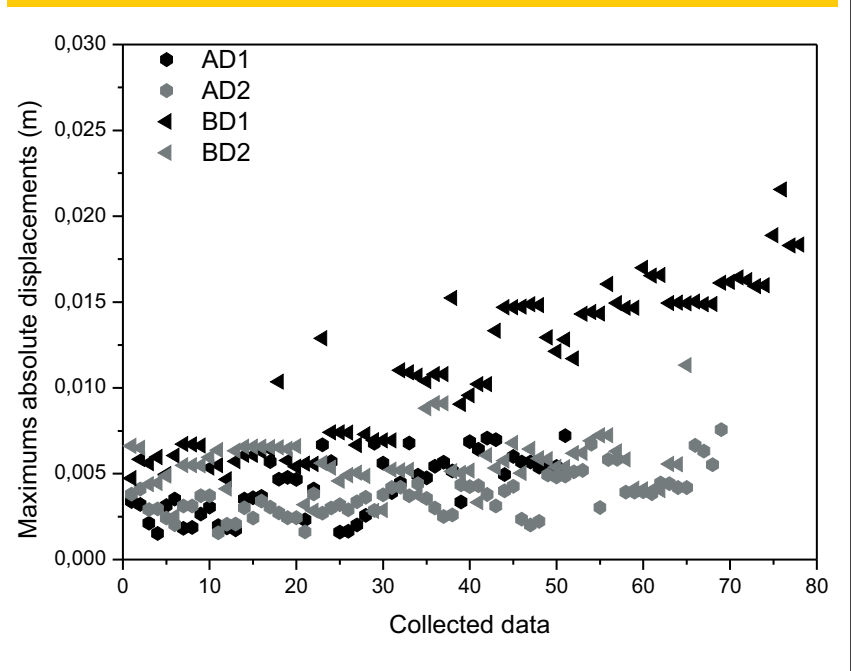

bi-axial optical accelerometer and a new methodology for reliability assessment based on maximum relative displacements. The reliability assessment methodology uses acceleration data provided by an optical sensor implemented in the top of a water reservoir located in the University of Aveiro, which has the aim to make measurements about the structure's maximum relative displacement indirectly, in the longitudinal and transversal direction. From the maximum displacements collected by the monitoring system, the safety limit value was established and then the reliability indexes calculated. In this perspective, the reliability monitoring system based on bi-axial optical accelerometer presented high efficiency and easy implementation in field, besides a relatively low cost.

The methodology of reliability assessment proposed in this work proved of easy application and adequate to data collecting, especially by utilization of GEV as a way to improve the modeling of the structural behavior induced by action of random variables, as wind velocity, in the case of this work.

The moderate values of $\beta$ highlight the necessity of attention

\section{Figure 5 - Histograms and distributions of maximums displacements in the directions D1 and D2 for wind situation A and B}

25 HISTOGRAM DATA NUMBER $=51$ MEAN $=0,0043$

20 STANDARD DEVIATION $=0,00175$ SUM $=0,21922$

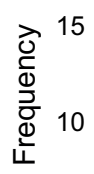

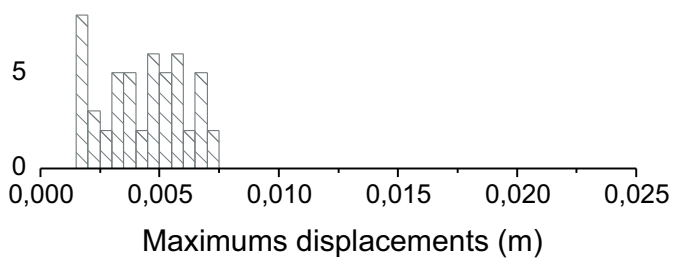

25

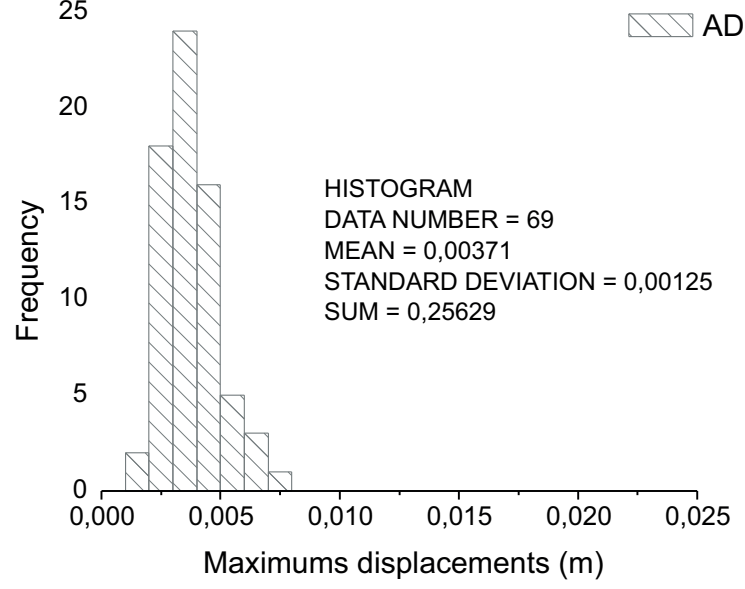

25 HISTOGRAM

DATA NUMBER $=78$ MEAN $=0,01121$

20 STANDARD DEVIATION $=0,00447$ SUM $=0,287454$

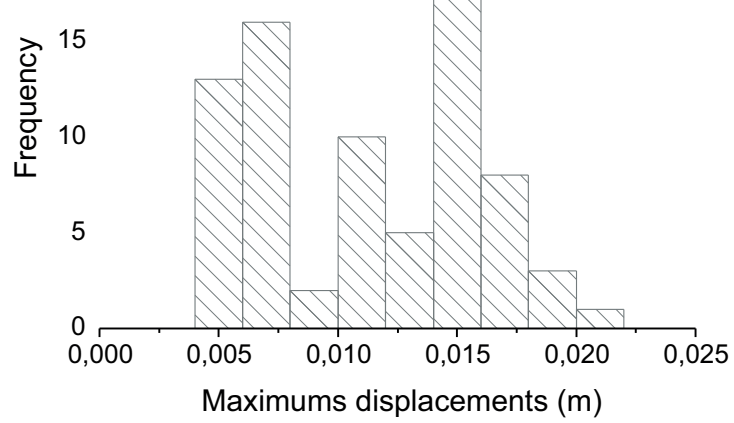

25

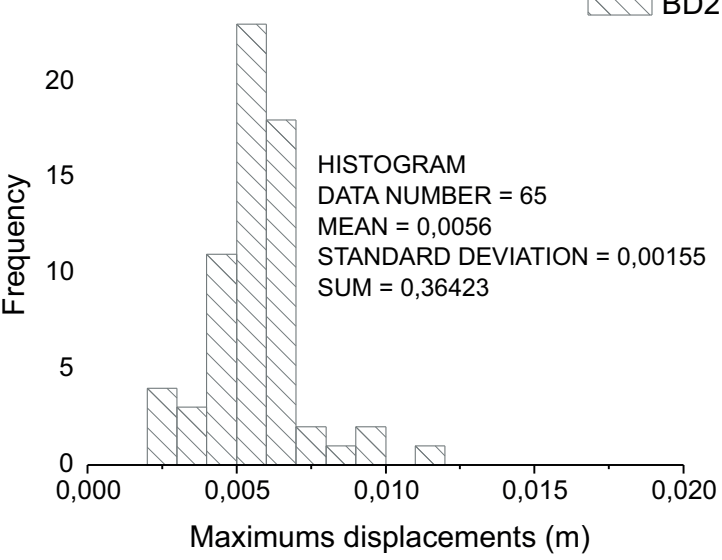




\section{Figure 6 - Histograms AD1(a), BD1(b), AD2(c) and BD2(d) and GEV curves}

a)

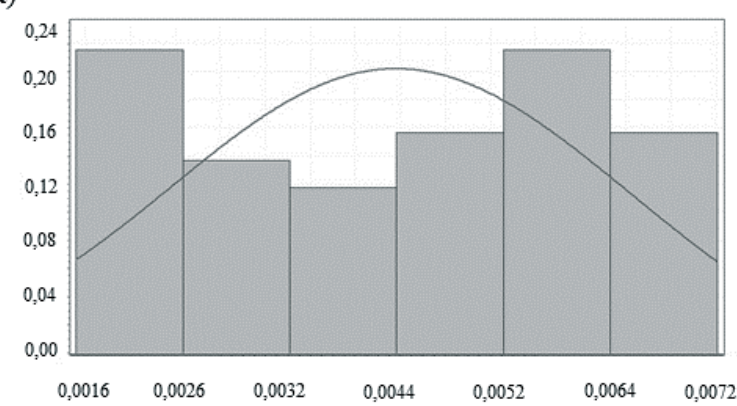

c)

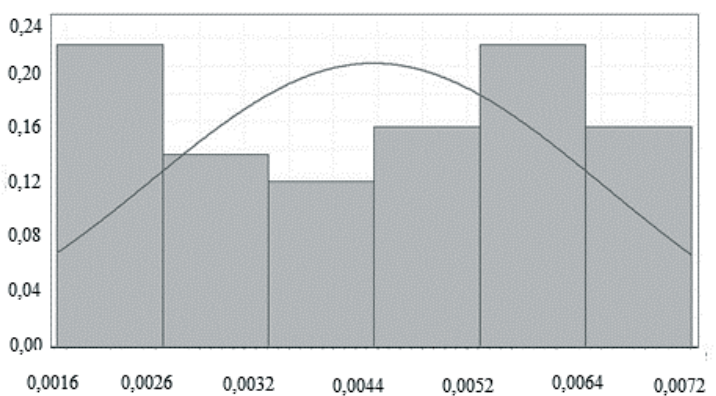

b)

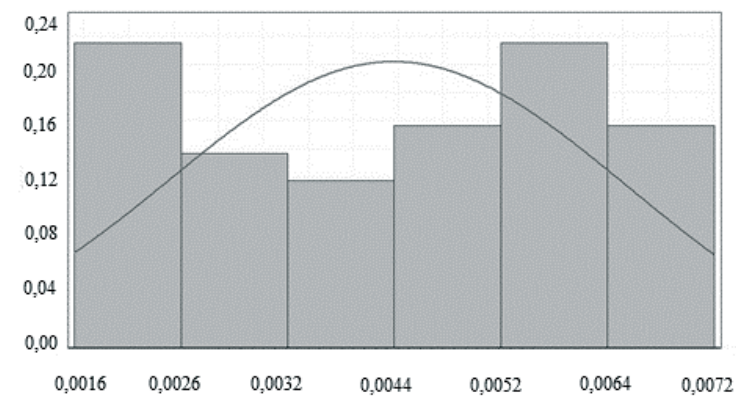

d)

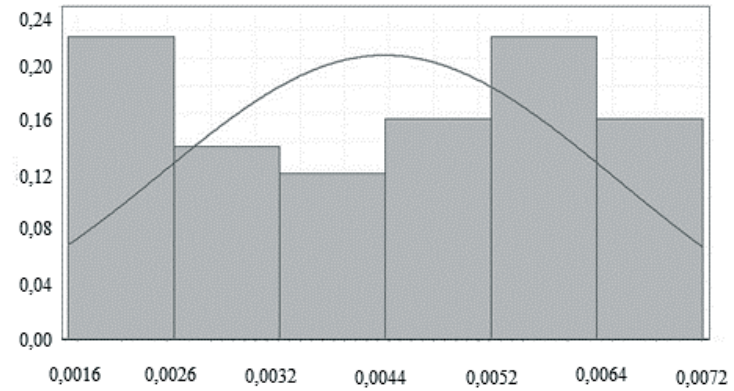

to structural behavior, in terms of transversal and longitudinal displacements, once they present a high probability of exceeding the safety limit, especially for natural frequency values near or higher than $0.900 \mathrm{~Hz}$ in the transversal direction, and when the wind velocity was equal or higher than $10.80 \mathrm{~m} / \mathrm{s}$.

\section{Acknowledgements}

Esequiel Mesquita acknowledge CAPES Foundation by Doctoral fellowship number 10023/13-5. Paulo Antunes acknowledge the Fundação para a Ciência e Tecnologia (FCT) by Post-doctoral

\section{Figure 7 - Water reservoir reliability index in function of the wind velocity, for directions D1(a) and D2(b)}
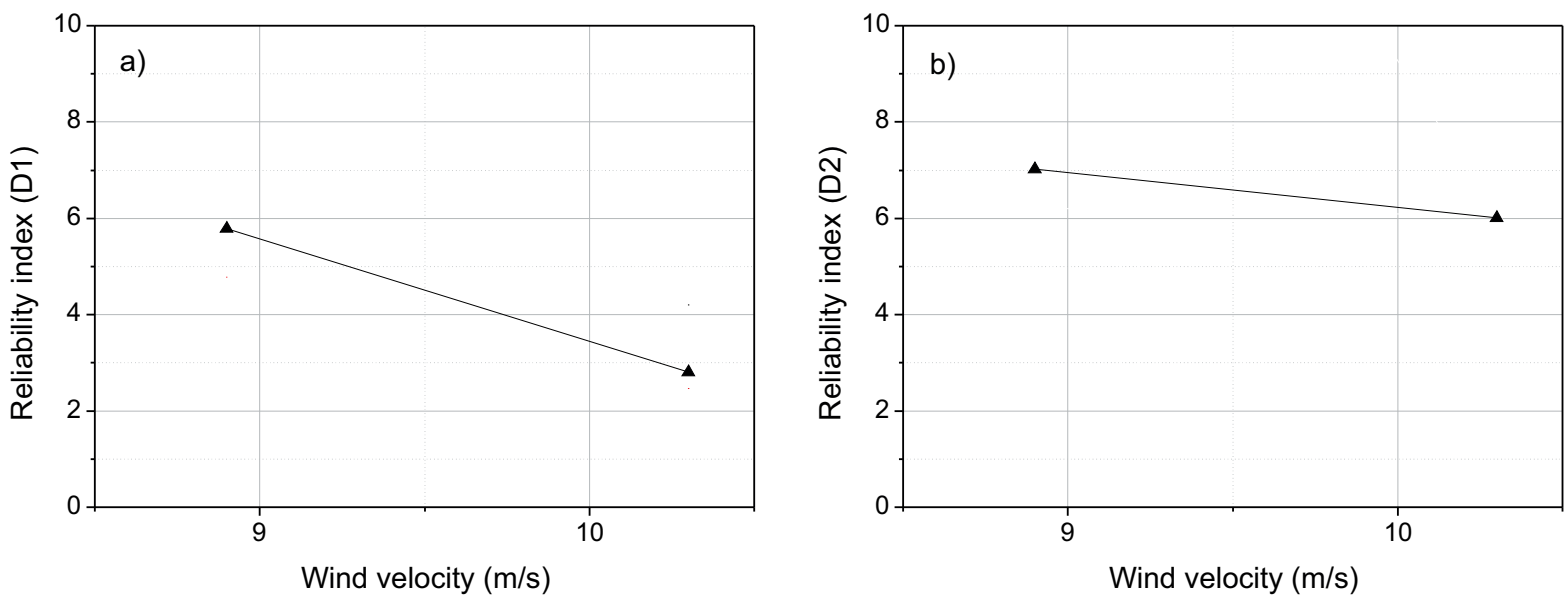


\section{Figure 8 - Reliability index prediction for next 100 years}

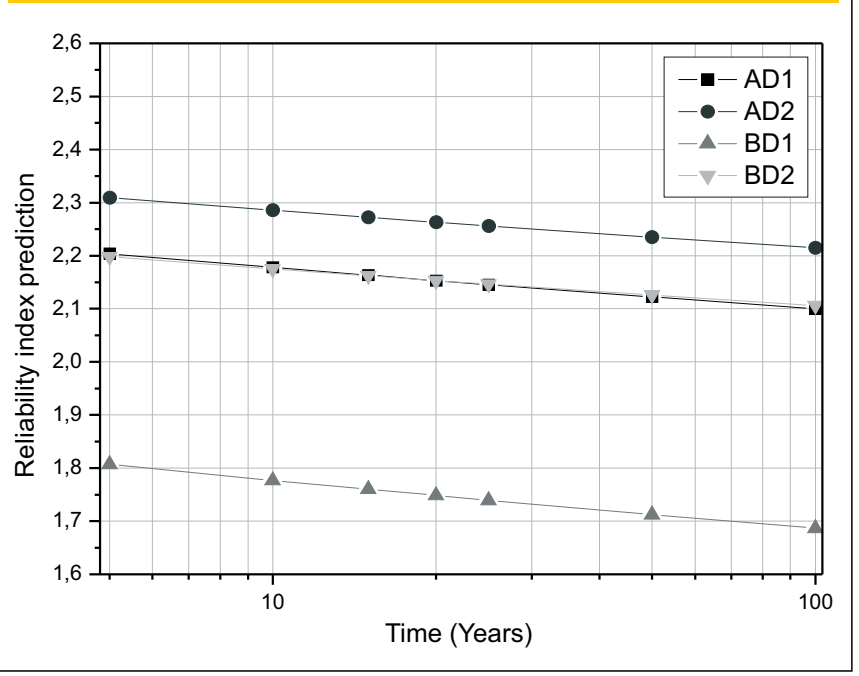

fellowship number SFRH/BPD/76735/2011.

\section{References}

[1] ABNT, "NBR 15575-2: Edificaçoes habitacionais - Desempenho. Parte 2: Requisitos para os elementos estruturais.," Rio de Janeiro, 2013.

[2] European Comittee for Staandardization, "European Standard 1990: Basis of structural design," Brussels, 2001.

[3] M. S. Laing, D. S. Homa, R. M. Harman, and C. H. LAMBERT, "Optical fiber sensor and method for adhering an optical fiber to a substrate." Google Patents, 2013.

[4] D. C. Betz, G. Thursby, and B. Culshaw, "Structural Damage Location with Fiber Bragg Grating Rosettes and Lamb Waves," vol. 6, no. 4, pp. 299-308, 2015.

[5] P. Antunes, J. Dias, T. Paixão, E. Mesquita, H. Varum, and P. André, "Liquid level gauge based in plastic optical fiber," Measurement, no. January, 2015.

[6] F. Domingues, T. Paixao, E. Mesquita, N. Alberto, A. Frias,
R. A. S. Ferreira, H. Varum, P. Antunes, and P. Andre, "Liquid hydrostatic pressure optical sensor based on micro-cavity produced by the catastrophic fuse effect," IEEE Sens. J., 2015.

[7] D. Diamantidis, "Report 32: Probabilistic Assessment of Existing Structures - A publication for the Joint Committee on Structural Safety (JCSS)," RILEM publications, France, 2001.

[8] C. Cremona, Structural Performance: probabilistic-based assessment, 1st ed. London: ISTE, 2011.

[9] P. B. R. Dissanayake and P. A. K. Karunananda, "Reliability Index for Structural Health Monitoring of Aging Bridges," Structural Health Monitoring, vol. 7. pp. 175-183, 2008.

[10] M. Liu, M. Asce, D. M. Frangopol, F. Asce, and S. Kim, "Bridge System Performance Assessment from Structural Health Monitoring : A Case Study," J. Struct. Eng., vol. 135, no. June, pp. 733-742, 2009.

[11] P. Antunes, C. A. Marques, H. Varum, and P. S. André, "Biaxial Optical Accelerometer and High-Angle Inclinometer With Temperature and Cross-Axis Insensitivity," IEEE Sens. J., vol. 12, no. 7, pp. 2399-2406, 2012.

[12] N. M. Okasha, D. M. Frangopol, D. Saydam, and L. W. Salvino, "Reliability analysis and damage detection in high-speed naval craft based on structural health monitoring data," Struct. Heal. Monit., vol. 10, pp. 361-379, 2010.

[13] A. S. Nowak and A. M. Rakoczy, "Reliability-Based Calibration of Design Code for Concrete Structures Load and Resistance Model - General Information," in 54 Congresso Brasileiro do Concreto, 2012, pp. 1-12.

[14] A. Haldar and S. Mahadevan, Probability, reliability and statistical methods in engineering desing, 1st ed. New York: John Wiley \& Sons, 2000.

[15] P. Antunes. Sensores ópticos para monitorização dinâmica de estruturas. Tese de Doutorado. Aveiro: Universidade de Aveiro, 2011.

Table 2 - Predicted values of water reservoir reliability indexes for the next 100 years

\begin{tabular}{|ccccccccccccccc|c|}
\hline Years & $\mathbf{T}$ & \multicolumn{3}{c}{ AD1 } & \multicolumn{3}{c}{ AD2 } & \multicolumn{3}{c}{ BD1 } & & BD2 \\
\hline 5 & 1825 & 0,014 & 0,986 & 2,204 & 0,010 & 0,990 & 2,309 & 0,035 & 0,965 & 1,807 & 0,014 & 0,986 & 2,198 \\
10 & 3650 & 0,015 & 0,985 & 2,178 & 0,011 & 0,989 & 2,285 & 0,038 & 0,962 & 1,777 & 0,015 & 0,985 & 2,175 \\
\hline 15 & 5475 & 0,015 & 0,985 & 2,163 & 0,012 & 0,988 & 2,272 & 0,039 & 0,961 & 1,760 & 0,015 & 0,985 & 2,162 \\
20 & 7300 & 0,016 & 0,984 & 2,153 & 0,012 & 0,988 & 2,263 & 0,040 & 0,960 & 1,748 & 0,016 & 0,984 & 2,153 \\
\hline 25 & 9125 & 0,016 & 0,984 & 2,146 & 0,012 & 0,988 & 2,256 & 0,041 & 0,959 & 1,739 & 0,016 & 0,984 & 2,146 \\
\hline 50 & 18250 & 0,017 & 0,983 & 2,122 & 0,013 & 0,987 & 2,235 & 0,043 & 0,957 & 1,713 & 0,017 & 0,983 & 2,126 \\
100 & 36500 & 0,018 & 0,982 & 2,100 & 0,013 & 0,987 & 2,215 & 0,046 & 0,954 & 1,687 & 0,018 & 0,982 & 2,106 \\
\hline
\end{tabular}

